\title{
The Effect of Working Place on Worker's Health in a Tannery in Bangladesh
}

\author{
Salauddin Biswas ${ }^{1 *}$, Tawhidur Rahman ${ }^{2}$ \\ ${ }^{1}$ University of Heidelberg, Heidelberg, Germany \\ ${ }^{2}$ Center for Sustainable Development (CSD), University of Liberal Arts Bangladesh, Dhaka, Bangladesh \\ Email: "salauddinmukta@yahoo.com
}

Received October 31 $1^{\text {st }}$, 2012; revised December $2^{\text {nd }}$, 2012; accepted December $16^{\text {th }}, 2012$

\begin{abstract}
This article investigates the causes of workers' health problems which are integrated with their daily work in the tanning industry, and with their daily life style pattern. The tanning industry has two opposing aspects; it brings economic prosperity for the country, on the other hand, it causes health problems for the workers. Moreover, it has detrimental effects on surrounding environment as well. The workers labor in polluted workplace inside of the industry, and live in unhygienic dwelling outside of the industry. While the workers practice daily life culture in personal life, they practice tannery culture in their work place, and both create health problems for them. Workers' health has relationship with surrounding areas, equipments, workplace floor, chemicals, ways of dealing with the machines, and so on, and all variables determine the workers' health individually or as a whole. Notably, one matter is not responsible for the suffering of the tannery workers. We need to consider it from the holistic point of view.
\end{abstract}

Keywords: Tannery; Hazaribagh; Workers’ Health; Environment; Pollution; Workplace; Heavy Work; Chemical Exposures; Personal Behaviors

\section{Introduction}

Leather is an exclusive, vastly multi-dimensional, and mutually dependent material all over the world. Now more than 500,000 people are working in this sector around the world, and the workers are increasing day by day (International Council of Tanners, 2011: p. 1, Qattous \& McCallin, 2009: p. 8). The Food and Agriculture Organization (FAO) shows that the world trade of commodities such as sugar (total, raw equivalent), coffee (green), cotton (lint), rubber (natural dry), rice (milled) and tea is not bigger than hides and skins trade. The growth rate of tanning materials are increasing in developing countries rather than in developed countries (2010: p. 29). This scenario prompts us to ask: how do developing countries like Bangladesh produce so many products? Who produces them? And whose health is impacted?

The Bangladeshi leather sector plays a vital role to expand the Bangladeshi economy in terms of export and domestic market (Penningroth, 2010; Sharif \& Mainuddin, 2003: pp. 3-4; Bangladesh Bureau of Statistic, 2007: p. 18). Currently, the number of leather and manufacturing units in Bangladesh has increased to 313 (International Labor Organization, 2008: p. 15). Among them, approximately 300 of the tanneries are situated in Hazaribagh, Dhaka. According to Billah et al. (2000: p. 1), about 100,000 people are engaged with this industry directly and indirectly. In the peak season ${ }^{1}$ between 12,000 and 15,000 people work in the tanneries and during the off season ${ }^{2}$ their num-

\footnotetext{
${ }^{*}$ Corresponding author.

${ }^{1}$ Peak season starts after Eid-ul-Fitr (the biggest Islamic festival inBangladesh). After Eid-ul-Azha (the second biggest Islamic festival), the work of tanning industry reaches its peak. During Eid-ul-Azha, the Muslim sacrifices animals like cows and goats for the satisfaction of Allah. The availability of the skins and hides makes peak season for the tanning industry.

${ }^{2}$ Approximately four months before Eid-ul-Fithr is off season, because during this time the laborers have no enough work.
}

ber decreases to between 12,000 and 8000 . However, "the leather tanning industry has been identified as one of the main causes of environmental pollution in the capital city of 8 million people” (Islam, 2000: p. 1). Hazaribagh is called "a cancerous problem” for Dhaka city (Huda, 2008).

Scholars, environment specialist, columnist, journalist, and NGO experts are very conscious about the environment of Hazaribagh and Dhaka. They discuss different aspect like water, soil, and air of the environment individually (Institute for Environment and Development Studies, 2003: pp. 8-66, AriasBarreiro et al., 2010: p. 473, Saha et al., 2001: p. 151, Bhuiyan, 2011: p. 633, Salam \& Gain, 2009: p. 152). They take "environment" as a watchword, and neglect the workers who live in that environment. They separate environment from the human being and other organisms. Very few scholars talk on laborer who work and live in Hazaribagh; even though almost all workers live in Hazaribagh with or without family. The workers suffer from double-edged problem: as an inhabitant, they face surrounding environment problem directly, and as a worker of tanning industry, they suffer from detrimental chemicals and wastes which are generated in the tannery itself.

This article deals with surrounding environments where the workers live, the kind of work they engage in, and the ways in which that work affects their health. Nuwayhid (2004: p. 1916) divided occupational health issues into two arenas-“an internal domain, which focuses on the workplace (microenvironment), and an external-contextual domain, which examines the wider social and global issues". We are in debt to Nuwayhid for using this terminology. As this article is about a certain area and industry, we use internal domain to mean the internal set up of the industry, and external domain to denote surrounding areas. However, if we take into consider our field work, and if we want to draw a clear sketch of workers' health of Moti tannery, 
we need to discuss the two domains, because two domains work individually or together to determine workers' health of Hazaribagh (Figure 1).

Internal domain deals with workplace where workers spend most of time of a day, and external domain covers the surrounding areas where they spend rest of time outside of working hours. Hazaribagh tannery workers' health problem is not only limited in either internal or external domain separately but it can be affected by the both domains together.

Work and health are integrated issues. Therefore, health problems of workers in the tanning industry include the kinds of work they engage in, the manner in which they work, and conditions of the work place. Firstly, the external domain where they live will be described. Secondly the interior setup that is called internal domain will be talked about. Internal domain includes floor organization, equipments, chemicals, workers' perceptions and attitude to the equipments and chemicals etc.

\section{Methodology}

This article is a result of an ethnographic research. Reflexive and Descriptive way of writing style is followed for this article so that after reading this study reader can imagine the real situation of Hazaribagh. Eleven weeks long field work based on qualitative methodology is conducted on Moti tannery, Hazaribagh, Dhaka. Moti tannery is a medium size industry with about 30 workers.

Hazaribagh Thana (police station) with an area 0.01456 sq. $\mathrm{km}$ or 1.456 acre is part of the Dhaka district. It is surrounded by Mohammadpur thana on the north, Kamrangir Char thana on the south, Dhanmondi and Lalbagh thanas on the east, Keraniganj thana and Buriganga river on the west (Bangladesh Asiatic Society). Total population is 127, 370 (Bangladesh Bureau of Statistic, 2001: p. 1) that makes this area is one of the most congested, noisy, high density and polluted area in Dhaka city.

Qualitative methods are followed for this study. Conducting field work in tannery is a great risk for the health of researcher in terms of malodor, hygienic problem, and harmful substances and so on. For this reason, it is not possible to conduct participant observation; however, several light works that are not detrimental for health are done by the researcher. Semi-structure interviews are rational for this study because workers are always busy, and they are controlled by supervisors, chemist or senior workers. Workers, officials, owners, family members of workers like wife, children and parents, and the neighbors like shopkeepers, small business man and people of other profes-

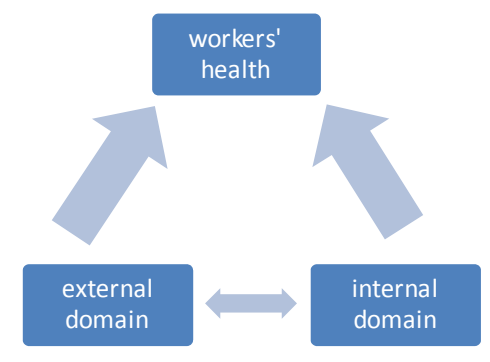

Figure 1.

How the two domains ${ }^{3}$ affect the health.

${ }^{3}$ The concept of two domains are taken from Nuwayhid, I. A. November 2004: 1916. Occupational health research in developing countries: a partner for social justice. American Journal of Public Health. 94 (11). sions take part in semi-structure interview. Focus Group Discussions (FGDs) are taken place for this study. However, as health is not only a biological or mental state individually, it is a holistic process; the qualitative methodology permits to draw a good sketch of health problem of the Moti tannery of Hazaribagh.

\section{External Domain}

Little (1999: pp. 254-255) argues that in general, environment as a term is frequently used "as a synonym for nature (i.e. the biophysical or nonhuman environment)", but this kind of practice formulates a "conceptual confusion because the environment of a particular human group includes both cultural and biophysical elements. By extension, the organism/environment dynamic, which is relational... and perspectivist, is often erroneously fused with the nature/culture dualism, which is essentialist and substantive." The environment includes all surroundings of any given person or object. According to the ecological point of view, the environment is all factors which have influence on the existing and reproduction of living organisms. The environment consists of "material factors whose presence is decisive for survival and development of living organism (oxygen, carbon, hydrogen), and factors regulating the living process” (Wolanski, 1980: p. 3). In Hazaribagh, tanning industry and nature are existing together side by side, and both are part of same environment. Tanning industry, as a part same environment, how affects the other parts (natural and non-natural) of same environment will take into consider in this article.

The sun is not in the mid-sky; however, it is too hot. There is no escapable way from the wind which carries a terrible odor. There are many narrow roads where not more than one man and one rickshaw can go side by side. Some roads are damaged, some are under construction, and some are only gravel, which creates dust everywhere. Furthermore, there are many turns within short distance, and many manholes without covers. Two narrow drains run along the two sides of the roads. Plastic bags, bottles and packets float in the drain. Black colored dregs from the drain pile up on the road. Open drains are used as a toilet. Different colored water flows in the drain for going somewhere. Dogs made of skin and bones roam here and there. Wasteswastes not only from tanneries, but also from the houses where the workers are living, are kept on the road. The city corporation has set out certain bins for throwing garbage in on the road, but they are all full. Huge amounts of garbage surround the bins, where reeking water and malodor (USAID, 2009: pp. 4-5) stream from. Mosquitoes and insects fly randomly. Tokai (street boys) search for things in the garbage. According to one worker, "This is a hell".

One informant says that crows like "wastes, rotten things", and, for this reason, a lot of crows live here. Besides crows there are no birds; besides dogs and cats, there are no animals. Therefore, in a environmental setting, in Hazaribagh, two or more creatures like workers, dogs, cats, crows, poor people make a "mutual ecology" (Fuentes, 2010: p. 600). Ecological anthropologists are mainly concentrated on the equilibrium between human being and environment (Vayda \& McCay, 1975: p. 294). It means that creatures make an ecological niche $e^{4}$ in a certain environment, which is influenced by social networks making agents (Barth, 1956: p. 1079, Popielarz \& Neal, 2007:

\footnotetext{
${ }^{4}$ Fredric Birth (1956: 1079) introduced the concept of the ecological niche, "the place of a group in the total environment, its relations to resources and
} competitors". 
pp. 65-84). In Hazaribagh area, unavailability of needs forces dogs, cats, crows to eat wastes, and compels the workers to live with wastes. Unavailability of human basic needs-food, cloth, shelter, education and treatment-creates such an environment which brings the workers, poor, vulnerable, marginal and so on under an umbrella.

Everyday up to 40,000 tones of tannery waste, including toxic water and untanned solid wastes like raw trimmings, fleshings, pelt-trimmings follows into the Buriganga River, the main water bodies for trading and ferry journey (Institute for Environment and Development Studies, 2003: pp. 8-66). Toxic water has harmful effects on the broad spectrum of organisms in the ecosystem (Arias-Barreiro et al., 2010: p. 473). The wastewater falls into ponds or lagoons, and this water contaminates underground water, which has dangerous effects on the human body and environment (Saha et al., 2001: p. 151; Bhuiyan et al., 2011: p. 633; Andreas et al., n.d.: p. 24). People collect drinking water either from a tube well or from a pipe to drink. But most of the basti people use water from ponds, doba, or Jhil (all are sources of water) for their daily use. Due to water pollution, life of water species is negatively affected (Islam et al., 2011: pp. 409-419, Arias-Barreiro et al., 2010: p. 472). Hossain et al. (2007: pp. 397-416) shows that how the waste (if it is reused) is harmful not only for Hazaribagh, but also for uncountable numbers of people. It can be the cause of large number of illness such as allergy, eczema and dermatitis (ibid). Tannery creates dusts, fumes and malodors which can affect different part of the lungs (Salam \& Gain, 2009: p. 152, Tanimowo, 2000: p. 71, Schwartz, 1994: p. 36). Solid wastes and toxic water are mainly generated in the tanneries, and the main sufferers are those people, the workers, who live in the centre and surrounding areas of Hazaribagh.

Bangladesh has to pay a high cost for environmental pollution because of leather industry. Islam et al. (2011: p. 418) identify mismanagement, inferior technologies, lack of facilities for treating industrial wastes, wrong approach towards industrialization as causes of environmental pollution. On the other hand, Liverman et al. (1997: p. 14) identify many ingredients of chemicals remain in environment for a long time for the sufferings "vulnerable populations such as children, the elderly, the chronically ill, minorities, and the poor may be at increased risk of harm related to environmental contamination because of biological and demographic factors, including where they live”.

\section{Internal Domain}

\section{Scattered Floor}

Wet floor and unplanned setup of the machines can be a great risk for the workers' health. In workplace of Moti tannery, unplanned setup of the machines creates a considerable obstacle for the movement of workers on the floor. The workplace-in the sense of arrangement of the machines on the floor, paths of walking, electric circulation, tools, water supply, lighting, ventilation, washroom, safety dress, place of rest, etc., create a indoor environment in the workplace which has direct influence like injuries on workers' health (World Health Organization, 2006: p. 2).

The narrow walking paths inside the Moti tannery cause many injuries of the workers. Basically, there are no specific paths on the floor. On the ground floor the paths are made between the machines, and between the manual workplaces and machines. Many machines such as drying, shaving, splitting, and coloring are set up on the ground floor. The first floor is decorated with five machines-a plate (to dry and iron), a begum (to iron and soft), a buffer (to make thin), a toggle (to dry), and fine skin measurement machine (to measure). The rest of the place is used as a drying and packing section. The second floor is almost empty; only three outworn machines are kept there. Like the ground floor, on the first and second floor there are no fixed paths to walk. The southern sides of first and second floors are open, while the ground floor is surrounded by other tanneries.

From the beginning of field work till the end many things are coped except the lighting system on the floor. The workers are used to working in this dim light. On the ground floor, when the blue materials (after chroming skin is called blue material), finished or non-finished materials are selected and scrutinized, they use an extra lighting system. Three or four tube lights are tied together with a plate that generates powerful lighting. Rafique $^{5}$ informs that he lost the power of his eyes because of low power of the lights. A lot of dusts and fumes make the lights dim. Furthermore, there is no chance of sun light on the ground floor to enter. The ground floor of the tannery is always wet due to lack of sunlight. In the winter season, sufferings of the workers become twice on the wet floor. As there are no heating system and arrangement of hot water, the workers toil in cold environment with cold water.

On the ground floor there are no windows or extra doors apart from the main gate. There are only two ventilators with adjuster fans; however, the adjuster fans do not work. Except for a couple of stand fans, there are no ceiling fans. Kalam acknowledged that during the summer season, over-sweating makes them tired, and creates breathing problems because of the scarcity of fresh air.

In Moti tannery the owners arrange water from the underground that is used for both drinking and production. Two pipes, one for coming water from underground and another for circulating water, are inside the tannery. The pipes are fixed with a pillar, and the water is reserved in an underground reservoir which is called tanky. However, the water tank has no cover. The mouth of the tank is equal level to the floor. RC-Cola bottle floats over the tank water. The workers put their dirty clothes on the pipes when they take rest, and water and fluids from the clothes drop in the tank water. Moreover, blue materials are pilled beside the tank. Chrome water from blue materials crawls and drips into the tank slowly. When water comes from the underground, it is preserved in a pot for whole day. But some workers drink the tank water directly. They think that tank water is good; it comes from the deep underground.

About the toilet, Pinto says, "If you enter in the toilet, you will die." There is no hygienic toilet culture in Moti tannery whatsoever. There is one toilet for all workers, men and women. The toilet is at the corner of the tannery-beside the drum of sulfuric acid. There is no cover of the door. One drum is in front of the workers' toilet, which is used as a cover of the door. There is no water supply in the toilet-the workers bring water from the pipe outside. It is completely unclean and full of malodor, adds Pinto.

Das and Grady (1983: p. 434) say "small changes in workplace dimensions can have considerable impact on worker productivity and occupational safety and health". In this statement the author says "small changes". It means that there is a stan-

\footnotetext{
${ }^{5}$ All names of the workers are pseudonym.
} 
dard scientific set up of instruments in workplace and the workers do one particular work. If one position of the floor, workplace or instrument is changed, occupational safety can be hampered. Therefore, the Moti tannery is an example of a nonstandard scientific set up-unplanned floor, old model equipments, unhygienic toilets and scattered drain on the work floor which make workers' health more extremely vulnerable.

\section{Bamboo Mara as a Symbol of Heavy Works}

In Bangladesh workers' muscle power is used widely, and it is the main requirement for the production (Ahsan et al., 1999: pp. 385-386). This statement is completely true for the workers of Moti tannery. There is no job in Moti tannery without using "heavy physical work" (ibid) or exerting extra pressure on body parts. In this paper, the term, "bodily works" is used to mean those activities which create extra pressure on body and cause workers' sufferings. Bodily works could be minimized by introducing some initiatives on interior arrangements and modern equipments claimed Jakir, one worker.

Waez, another worker, says "The body does not remain body". The workers think that multi dimensional works make pressure on different parts of body, and such kind of workloads can even destroy their stomachs. According to Jakir, "My mood becomes hot because of repetition of work". This repetition does not mean doing one work again and again; however, it means the unnecessary repetition of works. From the beginning to the end of production, the workers have to do one kind work several times in Moti tannery. Jakir claims that repetitions might be reduced if the place of the building, machines, interior set up and working tools are improved.

Carrying leathers, raw hides and skins from one place to another in same floor or in another floor is done manually. There is no elevator to carry materials from one floor to another floor. To carry the skins, the workers pile them up on a bamboo pole and carry it in pairs on their shoulders, which they call bamboo mara. They normally carry twenty to thirty skins and hides on the bamboo (weighing approximately sixty to hundred kilograms). With this bamboo they climb the stairs which have no railings, go from one corner to another corner crossing the wet floor, run from one machine to another machine within narrow paths. They use one metaphor to express this work; haler goru (the cow for plowing). This work is carried out by the each worker in the Moti tannery, excluding old, injured and women workers. Consequently, Rafiq utters: "during my young age, work was not work to me; I brought sixty skins with a worker who has died several years ago. This work has made me an aged person, weak and lame."

Babul, a worker, not so tall, and not more than 14 years old, is working in the toggle section (skin is put on a table that is entered in a hot chamber for extra drying). The toggle section is not on even floor, rather the floor is on a slope. The Toggle table is as tall as his chest. He has to press the table again and again standing on uneven floor. Iron made hooks are entered in the thumb for this special work. The consequence of this work is, according to Babul, "No skin remains in the thumb, feel chest pain". Moreover, this work is conducted by the heat of gas fire that makes this place constantly hot. "It creates jaundice in my nails and eyes”, adds Babul.

In Moti tannery, workers talk about their body frequently. For instance, they say dehe bamo (diseased body), durbol deho (week body), shorir kharap (bad body) and so on. The worker emphasizes the "physical entity" (Wolputte, 2004: p. 251) to mean the body, which is used during work in the industry. Mary Douglas divids the body into two paradigms, social body and physical body (1996: p. 69); however, Nancy ScheperHughes and Margaret Lock distinguish three different spheres of the body: 1) individual body, 2) social body and 3) body politic (1987: pp. 8-30). In Moti tannery, the physical body is the first significant body; because, for the worker the body means the physical body; "other bodies" place in second position. Mauss (1973: p. 70) said that the body is "from the concrete to the abstract and not the other way around". The owners of the tannery only see workers bodies as something "concrete" that they can exploit as a material element, but the workers, at the same time, also think that this is a part of an injustice done to them, because their bodies are not just something physical, they have "other bodies". To the workers "other bodies" mean mon or athma (mental body). For example, they say, "Mind is not good or mind does not want" frequently. But mon or athma is not their matter of discussion. For the workers, the physical body is an asset which is invested for earning money to sustain themselves.

According to Mauss (1973: p. 70), “The body is man's first and most natural instrument". The body is one of the main mysteries for anthropology due to its being simultaneously the mandatory entity in the social world, and the most indefinable. Social knowledge, practical knowledge and thinking processes give the meanings of the body. The body is a thing in the universe and an ongoing process that creates social action and is created by social action (St. Christian, 2002: pp. 14-15). The body is not an ending process, "but rather the end of one kind of body and the beginning of another kind of body" (Emily Martin, 1992: p. 121). When the workers stay at home, their physical bodies perform as they wish. For an example, they can have food or go to the market when they wish. It means that they can control their bodies according to their desire. But when the worker enters in the tannery, another body, which is proposed "controlled body", is produced on which the worker has no control. Controlled body is dominated by the tannery owners, supervisors, chemists or seniors. On the other hand, probably two bodies remain simultaneously. When they are in the tannery the familial body is hidden here, and the controlled body works. Again, when they go back at home, the familial body performs and controlled body remains hidden. This transformation from one body to another body occurs unconsciously. In every situation, body is controlled by the society. But by "control", means those controls which make pressure on other body states.

The body of the worker is considered only the obvious object; it has to be changed depending on the time and workload. At the beginning of their work, in the morning, the workers see the body as joibon kal (young age), and at the evening it turns to bura kal (old age). Their bodies also transform from dhir deho (slow body) to challu deho (quick body) depending on the work load. However, the words which are used to discuss their body performances do not only demonstrate transformation of the body; rather, these words are also used in a metaphoric sense.

Metaphor is "an expression which describes a person or object in a literary way by referring to something that is considered to have similar characteristics to the person or object you are trying to describe" (Cambridge Dictionaries Online). Wanger (1986: p. 5) describes metaphor as the mirror of matter, and it is relative, perfect and appropriate to describe the issue. 
By the metaphor of the body the workers try to express their vulnerability. For the workers of Moti tannery the body is a machine without feelings. It can work for a long time without rest. Like a machine, operators can control it. In western society the body metaphor is conceptualized as "an internal combustion engine or as a battery driven machine” (Helman, 2007: p. 32). The main concept of body metaphor is that the individual part of the body is like a machine, or it works like a machine. It is changable or replaceable. It has wave, and mind is a processor and storehouse of information and so on (ibid). However, the workers of the Moti tannery imagine the body in two ways; the body as a machine like western society, and another metaphor is feelings of human body like a machine. Actually, the machine has no life or feelings. Like machines they should not have any feelings, can not say "no" after a long time work. If they are injured a little, they have no time to care it. However, they use this sense to demonstrate their rest/unrest, time/overtime, good/bad, and movement or stable situation of the body in the work place.

\section{Dilemma of Chemical Exposure}

Chemical exposure as a topic is a hidden matter in Moti tannery. Normally, no workers talk about it. First question is asked "How do you come into contact with the chemicals?" Raju, a strong young man, about 20 years old, gives an indifferent answer: "there is any work without chemical." The Bangla meaning of "come into contact" is shongsporsho. Basically, Raju can not understand the word, shongsporsho; that is why he gives the answer in another way.

The workers have "their own language, their own interpretation, their own way of seeing it and "have their being" within it...they refashion an industrial world suit themselves" (Zonabend, 2009: p. 170). In Moti tannery, the workers use the words, laga or dhora to express chemical exposure. However, these words are not enough to express "chemical exposure". The Bangla meaning of "exposure" could be "shongsporsho"- the word that have used during the field work. It is an academic and high scale Bangla word. Therefore, many words are needed to describe chemical exposure to the workers. In this milieu, we can assume that the concept of chemical exposure is not an established truth in the tannery culture in where the workers are the members (workers' perception on chemicals and chemical exposure will be discussed later on). Currently, it is a matter for policy makers and scholars in Bangladesh.

Kalam uses one mask during mixing of dyeing powders but he and other workers do not use anything to protect them from the chemical smell. Through touching, inhaling and ingesting, the workers come in contact with the toxic chemicals. But for them, when the chemical gaye lage (comes in contact with the body); it is chemical exposure. Chemicals, or more precisely, toxic chemicals, are dose-dependent substances. A non-toxic substance might be toxic if the dose is very high, and a heavy toxic substance can be safe if the dose is not too high enough. (Hill, 2010: p. 57). In the tannery, the owners have no relationship with the workers; clever supervisor considers the workers' bodies as machines that can be control however he likes. No persons or organizations who can decide what is toxic or none toxic are visible during field work.

After reviving the skins and hides on the main road, the workers bring them into the tannery. They have no vehicle for carrying them except their heads. Salt from skins and hides fall on the head and the body. Salt was given on skins almost one month ago. The workers perceive it as regular salt rather than chemical. It is the first contact the workers have to a chemical. One question, "Is salt a chemical?” has asked almost all workers. Aside from Khair who was in Lebanon every worker believes that salt is not a chemical. Even lime is not a chemical to them. To them, chemicals are powder and liquid which have a distinct smell and color.

During the soaking (a process of removing blood, dung and other dirt), water, antiseptic and detergents are used to clean the skins and hides. In the same way, during unhairing (to remove hair), liming (to swell up the flesh), de-liming (to remove the lime), batting (to remove the rest of hairs) and tannings different types of chemicals are used. Generally, the workers do not touch the chemical directly, but come in contact in different ways. The before mentioned processes are conducted through the drums. For transferring chromed skins from one drum to another, they use either iron made angta (equipment with which one pitch of skin can hold) or hands. Furthermore, after processing skins in drums, they are put on the floor. Poisonous chemical water comes out and wet the floor. The workers walk on them without any safety shoes. When they pile up blue or chrome materials, they come in contact with chemicals again and again.

The second stage of the contact with chemicals starts during the re-chrome and dyeing. Normally, Kalam, Jakir and Taher are responsible for this work. They collect different kinds of chemicals and dyes from different places in the tannery. During the use of sulfuric acid, they are cautious; however, other chemicals are carried just like water. Most of the workers consider that Kalam, Jakir and Taher are under dangerous threat because they have direct contact with the chemicals, while others have indirect contact. To them, direct and indirect contact means the place of the work and type of the work. Touching or transferring chrome leather is not direct contact for them, because it comes via water and materials.

The third stage of chemical exposure begins when skins go for final production machines. For each machine there are multiple workers working together. One person collects or holds the skins up, another one or two persons put it in the machine. Another one or two people hold the processed materials. Therefore, for one stage of work more than one person comes in contact repeatedly with chemicals. Aside from few workers (women, sick and old), no one has any set work. This is another way to come in contact with chemicals through multiple tasks. This system of the work makes workers more susceptible to chemical exposure.

\section{Personal Behaviors}

Personal behaviors cause of chemical exposure in Moti tannery. The workers of Moti tannery consider that they have no jhuki (risk) in chemical exposure; rather they are at risk when they work with machines. Nuronnobi who mainly works with fleshing machine (to separate fat and flesh from the skin) says, "What kind of risk chemicals have? Risk is in this work! Anytime, hand can go out. Adnan worked with me. One day we were working together. Suddenly shouting! In a moment, I saw, he has no wrist. Now he is a man without hand, lives in village, Barisal.” Like Nurunnabi other workers also do not believe in chemical risk. One reason for not believing in chemical risk could be visibility. The dangerousness of chemical cannot be 
seen in normal settings, on the other hand, machinery risk such as injury or accident can always be seen. In tannery, risk is everywhere: in every work, in every machine, and in every chemical. Therefore, according to my field work, like Dauglas \& Wildavsky it would be better to be called "danger" rather than risk because "there are also risks that are unknown" (1982: p. 221). For the toxicologist, risk depends on experimental data, safety factors, probability and judgment (Olajos \& Salem, 2000: p. 269). But analyzing risk creates another risk if the "underlying process" (Roberts, 2009: p. 23) is not discussed. The quantitative approach of public health uses the risk factors as variables that interpret or reject individuals to ill health; it allows individuals into low risk or high risk categories (Panter-Brick \& Fuentes, 2009: p. 5). However, risk perception and assessment in anthropology includes a holistic process, technological hazards, water contamination, toxic-waste, radioactive contamination, technology acceptance, risk perception and exposure to technology, disaster prone industry and culture, effect on society and culture and so on (Smith, 1996: p. 319). "Risk perception and assessment are grounded in the cultural norms and values that both govern and are embedded in the relationships that human communities have with their physical and social environments" (ibid).

The vushi (vushi is produced after shaving the wet blue materials) and saliva is used to stop bleeding if any one cuts their legs, fingers and hands. To prevent them from malodor or chemical gas, Monir acknowledges, they smoke. Rafique says, "Blue (one kind of processed leather that is made with chrome and other chemicals) is for making cold." If the workers burn their hands, they put it in the pile of blue materials. Chrome is one of the most harmful substances for the body; however, they use it without any hesitation. Cutting fingers and legs are a very common part of daily work of Moti Tannery. However, they have no first aid kit in the tannery. They use tannery waste that is full of chrome to save them.

After drinking water, the workers dry the mouth with the lungi (a piece of cloth that is used for lower portion of the body) that has probably been using for several weeks in the workplace. Using dirty dress and having dry food during the work is commonly seen in Moti tannery. For argumentation's sake, it could be put that they have not enough money to buy good clothes or they have not enough time to eat food, or they have no right place for having food. But this is not all correct. Personal behaviors and life styles which are embodied from personal life reflect as risk during their working life. "Each society has its own special habits...These "habits" do not just vary with individuals and their imitations, they vary especially between societies, educations, proprieties and fashions, prestiges. In them we should see the techniques and work of collective and individual practical reason (Mauss, 1973: pp. 71-73).” They learn the behavior and lifestyle from the society in which they are born in, and from the new society or environment where they work. Therefore, worker's personal behavior/lifestyle that is responsible for risk is a collective arrangement.

"Poison destroys the poison" is a common proverb in Bangla language as well as in Moti tannery. And even, the workers practice this proverb in their daily lives in Moti tannery. The workers enjoy leisure time from 10:00 AM to 10:15 AM, only fifteen minutes. They wash their hands before having tiffin in leisure time. All workers, including children, use chemicals like LD (EMMULSOL DD) to clean their hands. Suvo, a child worker says, "It is LD (EMMULSOL DD), we use it as soap". He could not give any reason for using LD as soap.

Every workers in Moti tannery use LD as soap. LD is used almost for every procedure in tannery for productions. This chemical is used for removing the dirt from the skins and hides. The common perception of the workers is LD cleans their hands like skins and hides. Therefore, they use it for cleaning their hands before eating. Nurunnobi gives further information about LD. He says "Our work is so dangerous... these skins and hides are left for many days, many germs are created in them, and chemicals create many germs... this $L D$ demolishes germs and poisons." The inscription of the drum that contains LD has been checked. According to the inscription the real name is EMMULSOL DD. "Avoid contact with skin" is written on the drum. Jakir shows another substance that was fat. The real name of fat is SULTIT CR. The workers also use it to clean their hands. If the dye spills on their hands, and LD or fat does not work, they use sulfuric acid with the water. These chemicals are used for cleaning working dress if they have no soap there. The workers use chemicals to protect themselves from chemicals.

"Chemicals are double-edge swords" (Penningroth, 2010: p. $1)$; it is good and harmful for the society. The chemicals or the workers (as a member of society) do not determine chemicals as a good or bad substance. Organizations or persons who are responsible for indicating good or bad should do this work. End of the day truth is workers are the main sufferer from chemical exposure because they have no opportunity to avoid it.

\section{Conclusion}

This study argues that the health of the workers can be affected by the environment, workplace, kinds of work, way of work, society and culture, and personal behaviors and lifestyle. The health problems of the workers involve a holistic process, rather than just one factor, and all factors are integrated with the workers' lives. The workers control machines and tools, and also the other way around, machines and tools control the workers' body. Therefore, the interior set up of the industry dominates the range of health problems of the worker, because the workers' first threat comes from the inside of the tannery where they work. Furthermore, outdoor environments, neighbors, society, culture and ecology influence the workers' body because they live in these variables. The physical body is the main asset for the workers. They invest it in order to achieve better lives. They emphasize on the visible body that they can use. To visualize the suffering of their body and everyday life, the workers use different kind of metaphors. However, some of their metaphors are different from western thought. They use body metaphor not only to describe the body construction, but to illustrate their condition.

The common slogan of many disciplines, including public health, is that chemical exposure is very harmful for the body, or chemicals are dose-dependent substances. This is true, and we of course need them. At the same time, however, we need to know the reasons of chemical exposure. This paper illustrates that chemical and risk is a stagnant theme. The actors decide the frequency of chemical exposure and risk. The actors are dominated by the society and culture. Therefore, health problems of the workers are not only involving biological entity, but the creation of the respective society and culture. Society and 
culture create the working place conditions which have great impact on workers' health.

\section{REFERENCES}

Ahsan, M. R. et al. (1999). Work-related problems in metal handling tasks in Bangladesh: Obstacles to the development of safety and health measures. Ergonomics, 42, 385-396. doi:10.1080/001401399185739

Andreas et al. (n.d.). Indian leather sector report. Sector overview and SWOT analysis. India: ASIAPROECO.

Arias-Barreiro, C. R. et al. (2010). Ecotoxicological characterization of tannery wastewater in Dhaka, Bangladesh. Journal of Environmental Biology, 31, 471-475.

Bangladesh Bureau of Statistics (2001). Household, population, sex ration and literacy rate-2001. Upazila/Thana: Hazaribagh Thana. Dhaka: Bangladesh Government.

Bangladesh Bureau of Statistic (2007). Report on Bangladesh Census of Manufacturing Industries 2001-2002. Dhaka: Bangladesh Bureau of Statistic.

Bangladesh Asiatic Society (2011). Banglapedia. URL (last checked 24 December 2011).

http://www.banglapedia.org/httpdocs/HT/T_0047.HTM

Barth, F. (1956). Ecological relationship of ethnic groups in swat, North Pakistan. American Anthropologist, 58, 1079-1108. doi:10.1525/aa.1956.58.6.02a00080

Billah, S. M. R. et al. (2000). Heath of the tannery workers. Dhaka: SHED.

Bhuiyan, M. A. S. et al. (2011). Investigation of the possible sources of heavy metal contamination in lagoon and canal water in the tannery industrial area in Dhaka, Bangladesh. Environmental Monitoring and Assessment, 175, 633-649. doi:10.1007/s10661-010-1557-6

Cambridge Dictionaries Online (2012). URL (last checked 17 January 2012).

http://dictionary.cambridge.org/dictionary/british/metaphor?q=metap hor

Das, B., \& Grady, R. M. (1983). Industrial workplace layout design. An application of engineering anthropometry. Ergonomics, 26, 433-447. doi:10.1080/00140138308963360

Douglas, M. (1996) Natural symbols. London: Routledge.

Dauglas, M., \& Wildavsky (1982). An essay on the selection of technological and environmental dangers. Risk and Culture. Berkeley, CA: University of California Press.

Food and Agriculture Organization (2011). World statistical compendium for raw hides and skins, leather and footwear 1990-2009. Rome: Food and Agricultural Organization of the United Nations.

Fuentes, A. (2010). Naturalcultural encounters in Bali: Monkeys, temples, tourists, and ethnoprimatology. Cultural Anthropology, 25, 600624. doi:10.1111/j.1548-1360.2010.01071.x

Helman, C. G. (2007). Culture, health and illness. London: Hodder Arnold.

Hill, M. K. (2010). Understanding environment pollution. UK: Cambridge University Press. doi:10.1017/CBO9780511840654

Hossain, A. M. M. M. et al. (2007). Heavy metal concentration in tannery solid wastes used as poultry feed and the ecotoxicological consequences. Bangladesh Journal of Scientific and Industrial Research, 42, 397-416.

Huda, K. M. N. (2008). Municipal solid waste management. Bangladesh perspective. Dhaka: Academic Press and Publishers Library.

Institute for Environment and Development Studies (2003). Aquatic ecology and dangerous sustances: Bangldesh perspective. Dhaka: IEDS.

International Labor Organization (2008). Decent work country program, Bangladesh. International Labor Office.

International Council of Tanners (2011). Introduction to leather. URL (last checked 12 July 2012).

http://www.tannerscouncilict.org/introtoleather.htm

Islam, K. M. N. et al. (2011). Efficiency of different coagulants combination for the treatment of tannery effluents: A case study of Bang- ladesh. African Journal of Environmental Science and Technology, 5, 409-419.

Islam, T. (2000). Hell for leather. Asia Times. http://www.atimes.com/ind-pak/BF23Df01.html

Liverman, C. T. et al. (1997). Toxicology and environmental health information resources. Washington: National Academic Press.

Little, P. E. (1999). Environment and environmentalism in anthropological research: Facing a new millennium. Annual Review of Anthropology, 28, 253-84. doi:10.1146/annurev.anthro.28.1.253

Martin, E. (1992). The end of the body? American Ethnologist, 19, 121140. doi:10.1525/ae.1992.19.1.02a00070

Mauss, M. (1973). Techniques of the body. Economy and Society, 2, 70-88. doi:10.1080/03085147300000003

Nuwayhid, I. A. (2004). Occupational health research in developing countries: A partner for social justice. American Journal of Public Health, 94, 11. doi:10.2105/AJPH.94.11.1916

Olajos, E. J., \& Salem, H. (2000). Risk assessment and risk management: Pathways toward process enhancement. In H. Salem, \& E. J. Olajos (Eds.), Toxicology in risk assessment (pp. 269-310). Philadelphia, PA: Tailor \& Francis.

Panter-Brick, C., \& Fuentes, A. (2009). Health, risk, and adversity: A contextual view from anthropology. In C. Panter-Brick, \& A. Fuentes (Eds.), Health, risk and adversity (pp. 1-12). New York: Berghahn Books.

Penningroth, S. (2010). Essentials of toxic chemical risk. science and society. New York: CRC Press. doi:10.1201/9780203022627

Popielarz, P. A., \& Neal, Z. P. (2007). The niche as a theoretical tool. The Annual Review of Sociology, 33, 65-84. doi:10.1146/annurev.soc.32.061604.123118

Qattous, M., \& McCallin, T. (2009). A mission for accomplishment of a comprehensive sector study regarding the opportunities of complementarities and Industrial Integration in the Leather and Shoes Sector in the member countries of the Agadir Agreement (Egypt-Jordan-Morocco and Tunisia). Amman: ATU.

Roberts, C. (2009). Understanding health. In C. Panter-Brick, \& A. Fuentes (Eds.), Health, risk and adversity (pp. 13-25). New York: Berghahn Books.

Saha, G. C. et al. (2001). Groundwater contamination in Dhaka City from tannery waste. Journal of Civil Engineering, 29, 151-166.

Salam, F. M. A., \& Gain, P. (2009). Leather industry: Environmental pollution and mitigation measures. In P. Gain (Ed.), Investigative reports: Environment and human rights (pp. 150-157). Dhaka: SEHD.

Scheper-Hughes, N., \& Lock, M. M. (1987). The mindful body: A prolegomenon to future work in medical anthropology. Medical Anthropology Quarterly, 1, 6-41. doi:10.1525/maq.1987.1.1.02a00020

Schwartz, J. (1994). Air pollution and daily mortality: A review and meta analysis. Environmental Research, 64, 36-52. doi:10.1006/enrs.1994.1005

Sharif, M. I., \& Mainuddin, K. (2003). Country case study on environmental requirements for leather and footwear export from Bangladesh. Dhaka: Bangladesh Centre for Advanced Studies.

Smith, A. O. (1996). Anthropological research on hazards and disasters. Annual Review of Anthropology, 25, 303-328. doi:10.1146/annurev.anthro.25.1.303

St. Christian, D. D. (2002). Elusive fragments. Making power, propriety \& health in Somoa. Durham: Carolina Academic Press.

Tanimowo, M. O. (2000). Air pollution and respiratory health in Africa: A riview. East African Medical Journal, 77, 71-75.

USAID (2009). Leather processing: Cleaner production. Fact Sheet and Resource Guide. USAID.

Vayda, A. P., \& McCay, B. J. (1975). New directions in ecology and ecological anthropology. Annual Review of Anthropology, 4, 293306. doi:10.1146/annurev.an.04.100175.001453

Wagner, R. (1986). Symbol that stand for themselves. Chicago: The University of Chicago Press.

Wolanski, N. (1980). Environmental hazard and the future of man. In I. P. Singh, \& S. C. Tiwari (Eds.), Man and his environment (pp. 1-28). New Delhi: Concept Publishing Company.

Wolputte, S. V. (2004). Hang on to yourself. Of bodies, embodiment, and selves. Annual Review of Anthropology, 33, 251-269. 


\section{S. BISWAS, T. RAHMAN}

doi:10.1146/annurev.anthro.33.070203.143749

World Health Oorganization (2006). Declaration on workers health. Stresa, Italy: WHO.

Zonabend, F. (2009). The nuclear everyday. In M. Mollona et al. (Eds.),
Industrial work and life. An anthropological reader (Vol. 78, pp. 167-188). New York: Berg, London School of Economics Monographs on Social Anthropology. 